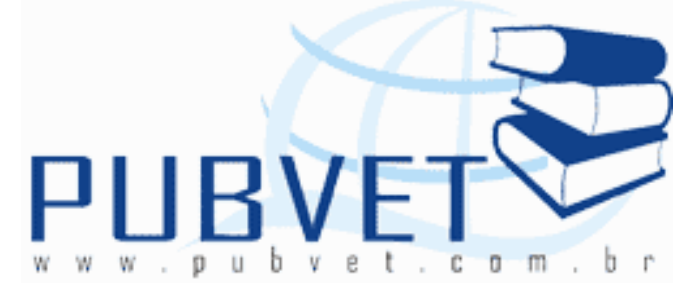

PUBVET, Publicações em Medicina Veterinária e Zootecnia.

\title{
Hérnia umbilical em caprino: Relato de caso
}

\section{Gerlan Vieira de Sousa ${ }^{1 *}$, Gerson Tavares Pessoa ${ }^{1}$, Lidiany Viana Pires ${ }^{1}$,}

Francisco Humberto da Silva Ribeiro ${ }^{2}$, Marcos Daniel de Sousa Ferreira ${ }^{1}$, Mayara Camuri Teixeira Lopes ${ }^{3}$, Severino Vicente da Silva ${ }^{4}$, Francisco Solano Feitosa Junior ${ }^{4}$

${ }^{1}$ Programa de Pós-graduação em Ciência Animal, Centro de Ciências Agrárias, Universidade Federal do Piauí, Teresina, Piauí, Brasil

2 Graduando em Medicina Veterinária pela Universidade Federal do Piauí, Centro de Ciências Agrárias, Universidade Federal do Piauí, Teresina, Piauí, Brasil

${ }^{3}$ Programa de Residência Médico-Veterinária, Universidade Federal do Piauí, Centro de Ciências Agrárias, Teresina, Piauí, Brasil

${ }^{4}$ Departamento de Clínica e Cirurgia Veterinária, Centro de Ciências Agrárias, Universidade Federal do Piauí, Teresina, Piauí, Brasil

* Autor para correspondência, gerlan.vet@hotmail.com

\section{Resumo}

As hérnias umbilicais surgem como massas arredondadas e macias localizadas na cicatriz umbilical. Uma hérnia umbilical surge porque a linha alba deixou de se fechar em volta do pedículo do cordão umbilical e em muitos casos isto é predisposto pela infecção moderada do resíduo umbilical. Muitas das hérnias umbilicais são hereditárias, e provavelmente são resultantes de caráter 
SOUSA, G.V. et al. Hérnia umbilical em caprino: Relato de caso. PUBVET, Londrina, V. 7, N. 13, Ed. 236, Art. 1558, Julho, 2013.

limítrofe poligênico, possivelmente envolvendo um gene importante. Até que se saiba mais acerca da herança e expressão para esse distúrbio, os animais não devem ser utilizados na reprodução. Por essa abertura poderá se projetar uma porção das vísceras abdominais, empurrando com ela uma bolsa do peritônio. A tumefação pode ser percebida como uma estrutura mais firme, se algum tecido adiposo ficou encarcerado e irredutível. Os animais com sinais gastrointestinais agudos (vômitos, anorexia) e massa umbilical dolorosa, firme e irredutível podem estar sofrendo encarceramento do intestino delgado, causados por uma obstrução. O presente relato descreve a ocorrência de hérnia umbilical, tendo como conteúdo alças intestinais, em um caprino de dois meses de idade, sem raça definida e a sua resolução através de uma intervenção cirúrgica. A terapêutica adotada incluiu a redução cirúrgica da hérnia, porém, sem a abertura do anel herniário. O animal apresentou excelente recuperação sem complicações pós-operatórias.

Palavras-chave: Hérnia, umbilical, caprinos.

\title{
Umbilical hernia in goats: Case report
}

\begin{abstract}
Umbilical hernias appear as rounded masses and located in soft navel. An umbilical hernia arises because the left linea alba to close around the pedicle of the umbilical cord and in many cases it is predisposed moderate infection of umbilical residue. Many umbilical hernias are hereditary, and probably result from polygenic character borderline, possibly involving a gene important. Until more is known about the inheritance and expression for this disorder, the animals should not be used for breeding. For this opening may design a portion of the abdominal viscera, pushing her a pouch of peritoneum. The swelling can be perceived as a firmer structure, if any adipose tissue was incarcerated and irreducible. Animals with acute gastrointestinal signs (vomiting, anorexia) and umbilical mass painful, firm and unyielding may be suffering incarceration of the small intestine caused by an obstruction. This report describes the
\end{abstract}


SOUSA, G.V. et al. Hérnia umbilical em caprino: Relato de caso. PUBVET, Londrina, V. 7, N. 13, Ed. 236, Art. 1558, Julho, 2013.

occurrence of umbilical hernia, with the intestinal contents in a goat at two months of age, breed and its resolution through a surgical intervention. The adopted therapy included surgical reduction of the hernia, but without opening the hernia ring. The animal showed excellent recovery without postoperative complications.

Keywords: Hernia, umbilical, goats

\section{Introdução}

O termo hérnia se refere aos órgãos que se deslocam de sua localização anatômica normal para uma cavidade neoformada ou natural através de um orifício anatomicamente fraco. As hérnias comumente encontradas nos animais domésticos são: hérnia diafragmática, hérnia inguinal, hérnia escrotal, hérnia umbilical, hérnia abdominal traumática, hérnia hiatal, hérnia incisional e hérnia perineal (HUNT, 2006).

O umbigo consiste de três estruturas que sofrem alterações anatômicas e funcionais por ocasião do nascimento. As estruturas umbilicais intra-abdominais consistem de uma veia, duas artérias e o úraco. A gelatina de Wharton envolve as artérias, veias e úraco. Estes vasos passam da cavidade abdominal para o exterior, através de um anel epitelial que atravessa a musculatura abdominal. Dentro da porção extra-abdominal existem duas veias umbilicais que ao penetrarem na cavidade abdominal se unem, dirigindo-se cranialmeníe ao fígado. Em sentido caudal, as artérias dirigem-se à artéria hipogástrica e o úraco à bexiga. Os vasos umbilicais intra-abdominais, inclusive o úraco, são envolvidos pelo peritônio (PRATES, 2008).

A região umbilical dos neonatos sofre dramáticas alterações logo após o nascimento. Durante toda a vida fetal, o umbigo foi a porta de comunicação entre o feto e a mãe. Por ele chegava sangue arterial materno, rico em nutrientes e oxigênio. Através das veias umbilicais, o feto eliminava o $\mathrm{CO} 2$ e através do úraco ocorria à eliminação da urina. Entretanto, logo após o nascimento o umbigo perde totalmente sua função e involui rapidamente. Os vasos (veias e artérias) umbilicais se fecham juntamente com o úraco e a 
SOUSA, G.V. et al. Hérnia umbilical em caprino: Relato de caso. PUBVET, Londrina, V. 7, N. 13, Ed. 236, Art. 1558, Julho, 2013.

parede muscular também se fecha. O seu fechamento inadequado é denominado hérnia umbilical (LISCHER e STEINER, 1994).

A hérnia umbilical aparece através do umbigo, que é um ponto fraco natural. O umbigo é o local por onde o feto foi alimentado durante a vida uterina. No umbigo não existe proteção muscular como no restante da parede abdominal, ele se mantém fechado por uma fibrose constituída por tecido cicatricial (REBHUM, 2000).

As hérnias podem ser classificadas de acordo com a frequência, época de aparecimento, estrutura, percurso, relação anatômica, conteúdo, localização e topografia (SOUSA e ABÍLIO, 2007).

De acordo com as estruturas, as hérnias podem ser classificadas em falsas ou verdadeiras. As hérnias falsas possuem o saco formado pela pele, subcutâneo e fáscia ou qualquer outra estrutura. Já as verdadeiras, apresentam 0 anel hernial e o saco é constituído de peritônio parietal circundando o conteúdo hernial (SOUSA e ABÍLIO, 2007). O saco hernial apresenta uma camada peritoneal interna e uma camada externa de pele e, especialmente de hérnias maiores, pode conter omento, alças de intestino delgado e grosso (STOCKWELL e FISHER, 1989). Provavelmente essas hérnias têm origem genética, mas podem ocorrer como seqüelas de infecções umbilicais. A abertura na parede abdominal é percebida como um anel à palpação (PUGH, 2004).

De acordo com Bojrab (1996), as hérnias umbilicais são quase sempre congênitas e resultantes de um defeito no desenvolvimento embrionário. A parede abdominal ventral é formada embriologicamente pela migração das pregas cefálicas, caudal e das duas laterais, formando uma abertura através do qual passam vasos sanguíneos umbilicais, duto vitelino e a haste do alantóide. Após o nascimento, a abertura (anel umbilical), se fecha entre a ruptura de seu conteúdo, restando apenas a cicatriz umbilical. Ocorrerá hérnia, se o anel umbilical não se formar apropriadamente, se for demasiadamente grande para permitir uma contração completa no nascimento ou não ocorrer contração. 
SOUSA, G.V. et al. Hérnia umbilical em caprino: Relato de caso. PUBVET, Londrina, V. 7, N. 13, Ed. 236, Art. 1558, Julho, 2013.

Hérnias de até cinco centímetros de diâmetro são consideradas pequenas e mais comuns (ADAMS, 1990) e, frequentemente, ocorre involução espontânea no primeiro ano de vida (ORSINI, 1997). Entre as possíveis complicações dessas hérnias umbilicais estão o encarceramento intestinal e, com menor frequência, a hérnia de RICHTER e fístula retrocutânea (ORSINI, 1997 e WILKINS, 2004).

Esta alteração surge quando o processo involutivo da região umbilical apresenta uma falha no fechamento da musculatura abdominal. Alguns casos apresentam involução espontânea. Todavia, na maior parte das vezes só resta à opção cirúrgica para o tratamento. Trata-se de processo de base genética e sua ocorrência deve ser levada em conta na hora de se selecionar matrizes para o plantel (LISCHER e STEINER, 1994.).

O diagnóstico é basicamente clínico e deve fundamentar-se no exame semiológico local, com o animal em posição quadrupedal. Recomenda-se ainda, empregar no diagnóstico, técnicas radiográficas e ultrassonográficas (NGUHIU et al, 1991).

O sucesso do tratamento depende dos cuidados pós-operatório, diâmetro do anel herniário, tamanho e peso dos animais, presença de inflamação no local e da resistência dos tecidos localizados na borda do anel herniário (SILVA et al,1999).

No fechamento de hérnias (aquelas com diâmetro inferior a $4 \mathrm{~cm}$ ), grampos ou faixas de borracha podem ser úteis. O clínico deve sedar levemente o animal ou infiltrar anestésico local (lidocaína a $2 \%$ ) ao redor da hérnia. O animal deve ser mantido em decúbito dorsal por um auxiliar. Qualquer prolapso de vísceras no saco hernial deve ser recolocado na cavidade abdominal. Em seguida, o clínico introduz dois alfinetes de metal (podem-se utilizar alfinetes de fraldas) através da pele e nos lados opostos do anel hernial, próximo à parede abdominal. Aplica-se discreta tensão à pele do centro do saco umbilical, tracionando-a de modo que se afaste do abdômen. Quando se percebe que todas as vísceras saíram do saco hernial, coloca-se uma faixa elástica entre os alfinetes e a parede abdominal. Isso resulta em 
SOUSA, G.V. et al. Hérnia umbilical em caprino: Relato de caso. PUBVET, Londrina, V. 7, N. 13, Ed. 236, Art. 1558, Julho, 2013.

necrose isquêmica da pele. A pele se destaca e a lesão cicatriza em 7 a 14 dias. Em cordeiros, deve-se proceder à profilaxia para tétano. Esse método e outras técnicas de grampeamento são úteis em fêmeas e em alguns machos. No entanto, alguns machos podem apresentar assadura na pele. O clínico deve monitorar cuidadosamente o animal submetido a tal procedimento (PUGH, 2004)

A herniorrafia é o procedimento cirúrgico que deve ser realizado quando o anel hernial é superior a $5 \mathrm{~cm}$. Os animais podem ser sedados e à anestesia geral ou local. Faz-se tricotomia e preparação cirúrgica da área ao redor da hérnia. O clínico realiza uma incisão no saco hernial e introduz um dedo no abdome para assegurar que não há aderência das vísceras na porção interna do anel e que não há resquício umbilical aumentado ou infectado. Em seguida, extirpa o anel e fecha o defeito da parede abdominal. Esse fechamento pode ser feito simplesmente contrapondo a parede abdominal em sutura de colchoeiro horizontal (fio absorvível). Fechamento alternativo da parede abdominal é a sutura da membrana peritoneal em pontos separados e a sutura da parede abdominal de modo que um lado da hérnia seja colocado sobre o outro. A margem superior livre é suturada à parede oposta com um padrão "perto-longe-longe-perto". Os autores preferem não empregar técnicas cirúrgicas demoradas. O tecido subcutâneo pode ser suturado com pontos simples separados utilizando-se fio absorvível e a pele deve ser fechada em qualquer padrão de sutura preferida pelo clínico. Os animais devem ser submetidos à profilaxia para tétano e à antibioticoterapia. Devem ser monitorados, investigando-se sinais de septicemia e falha cirúrgica. Deve-se limitar a atividade física até 7 a 14 dias após a cirurgia (PUGH, 2004).

$\mathrm{O}$ presente relato teve por objetivo descrever um caso de hérnia umbilical, com conteúdo de alças intestinais, em um caprino macho, SRD, 2 meses de idade, cor preta, pesando $5 \mathrm{~kg}$, procedente de Teresina-PI, atendido na Clínica de Grandes Animais do Hospital Veterinário Universitário do Centro de Ciência Agrárias da Universidade Federal do Piauí. 
SOUSA, G.V. et al. Hérnia umbilical em caprino: Relato de caso. PUBVET, Londrina, V. 7, N. 13, Ed. 236, Art. 1558, Julho, 2013.

\section{Material e Métodos}

Deu entrada na Clínica de Grandes Animais do Hospital Veterinário Universitário do Centro de Ciência Agrárias no dia 22/09/2010 um caprino, nome mimoso, macho, SRD, de 2 meses de idade, cor preta, pesando $5 \mathrm{~kg}$ e ficha clínica com o número 1441/10 com procedência de Teresina.

\section{Anamnese}

Segundo o proprietário o umbigo do animal estava crescendo muito rápido há mais ou menos 15 dias.

\section{Exame clínico}

Durante a realização do exame clinico observou-se os seguintes parâmetros: Frequência Cardíca: 76 bpm; Frequência Respiratória: 18 mrm; Movimentos Ruminais: Normais e Temperatura Retal: 38,4 Co.

Após o exame clínico através da palpação abdominal constatou-se a presença de uma hérnia umbilical. $O$ anel herniário apresentava uma abertura de aproximadamente sete centímetros de diâmetros e o conteúdo do saco herniário podia ser reduzido manualmente numa manobra denominada de "taxe". Nesta ocasião foi indicada a herniorrafia.

\section{Tratamento Cirúrgico}

Após jejum hídrico e sólido de 12 horas, tricotomia da região operatória, antissepsia com álcool iodado a $5 \%$, o animal foi submetido a uma medicação pré-anestésica a base de xilazina a $2 \%$, por via intramuscular, na dose de $0,2 \mathrm{mg} / \mathrm{kg}$, seguido de anestesia local infiltrativa com xilocaína a $2 \%$ como vaso constrictor na dose $3 \mathrm{mg} / \mathrm{kg}$.

Tomado todos os cuidados pré-operatórios, iniciou-se o transoperatório com incisão elíptica ao redor do anel umbilical para em seguida divulsionar e separar os tecidos subcutâneos e musculares compreendidos na base do anel herniário (saco externo) que após liberação foi seccionado, seguido de interiorização abdominal do conteúdo herniário (epiplon). Realizou- 
SOUSA, G.V. et al. Hérnia umbilical em caprino: Relato de caso. PUBVET, Londrina, V. 7, N. 13, Ed. 236, Art. 1558, Julho, 2013.

se sutura de Wolf do anel herniário com fio de nylon n040 e redução dos espaços mortos com sutura continua e a dermorrafia com sutura simples separada (Figura 1).

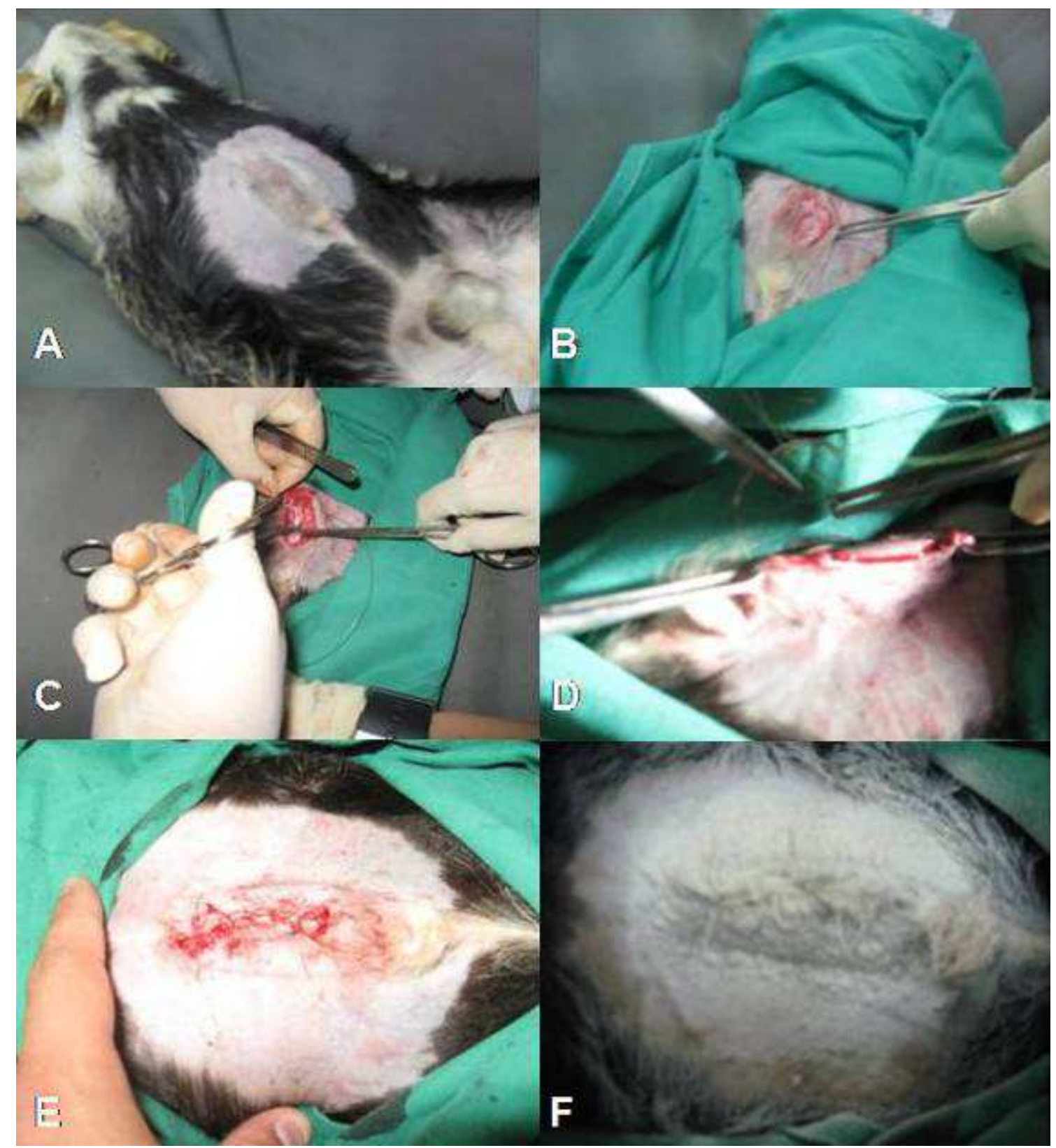

Figura 1. Descrição em seqüência cronológica da técnica cirúrgica adotada no caso. (A) Paciente em decúbito dorsal com tricotomia na região umbilical. (B) Divulsão da pele e tecidos subcutâneos. (C) Fechamento do anel herniário com pontos em X. (D) Redução dos espaços mortos com sutura do tipo Cushing. (E) Dermorrafia utilizando sutura do tipo Wolf. (F) Aplicação tópica de óxido de zinco na ferida operatória. 
SOUSA, G.V. et al. Hérnia umbilical em caprino: Relato de caso. PUBVET, Londrina, V. 7, N. 13, Ed. 236, Art. 1558, Julho, 2013.

O pós operatório constou de duas aplicações de penicilina associada à estreptomicina e diclofenaco sódico na dose $20.000 \mathrm{UI} / \mathrm{Kg} / \mathrm{IM}$ a cada 24 horas, flunixin meglumine na dose $2 \mathrm{~mL} / \mathrm{IM}$ durante três dias consecutivos e cuidados diários com a ferida operatória com óxido de zinco. A retirada dos pontos cutâneos se deu aos dez dias de pós-operatório, oportunidade esta em que o animal clinicamente recuperado recebeu alta.

\section{Resultados e Discussão}

A hérnia é facilmente diagnosticada à inspeção do umbigo. As manifestações de dor com inquietação, tentativa de lambedura, de coçar com os pés, estão associadas à aderência e suas complicações (inapetência. febre, peritonite, obstrução e hemorragia abomaso-intestinal, com falência orgânica e morte nos casos severos). A palpação tem que ser suave e firme, fornecendo ao examinador as características do conteúdo, de possíveis aderências, da redução total ou parcial do saco para a cavidade abdominal, como também, identificando o tamanho do anel herniário e a presença de constituintes do cordão umbilical. O diagnóstico clínico conduzirá ao tratamento, o qual na maioria dos casos é cirúrgico, com prognóstico favorável (PRATES, 2008).

Ainda segundo o autor a palpação profunda da cavidade abdominal possui valor diagnóstico para o reconhecimento de inflamações ascendentes das estruturas umbilicais, bem como na identificação do conteúdo de aumentos de volume na região umbilical do bezerro. O exame deve ser realizado com o animal em estação e em decúbito. A parede abdominal é palpada por pressão em direção caudal e cranial ao umbigo ao longo da linha média. Em seguida, os vasos intra-abdominais são palpados minuciosamente, a fim de se verificar o espessamento ou endurecimento dos mesmos, e até que ponto eventuais alterações umbilicais se estendem em sentido cranial ou caudal. Nos casos de aumento de volume circunscrito na região umbilical, a palpação tem a finalidade de verificar sua temperatura, consistência, sensibilidade à dor e a capacidade de redução, bem como a presença ou não de anel herniário. 
SOUSA, G.V. et al. Hérnia umbilical em caprino: Relato de caso. PUBVET, Londrina, V. 7, N. 13, Ed. 236, Art. 1558, Julho, 2013.

Foi diagnosticada uma hérnia umbilical neste animal através do exame físico de palpação, onde se pode palpar o anel herniário que possuía aproximadamente sete centímetros de diâmetros e o conteúdo herniário podia ser reduzido manualmente.

Assim como SMITH, 2006, e PRATES, 2008 o tratamento da maioria das hérnias em ruminantes é o cirúrgico. Este tratamento garante bons níveis de recuperação se a cirurgia for realizada no início da enfermidade, se o animal não fizer esforço e receber medicação adequada no pós-operatório. Quando as hérnias são complicadas, no caso das hérnias diafragmáticas o prognóstico é reservado ou desfavorável.

A técnica cirúrgica consiste em uma incisão elíptica, reposição do conteúdo herniário na cavidade abdominal e fechamento das bordas do anel. A redução pode ser feita com o saco herniário fechado ou, após a sua abertura. $\mathrm{Na}$ primeira situação as chances de contaminação bacteriana da cavidade abdominal são menores, porém o risco de recidiva é maior. No segundo caso ocorre o contrário, diminuem as recidivas, porém aumentam as possibilidades de peritonite (PRATES, 2008). Neste caso foi feito a redução da hérnia com o saco herniário fechado visando diminuir a contaminação. Foi feito uma incisão elíptica ao redor do anel umbilical para em seguida divulsionar e separar os tecidos subcutâneos e musculares compreendidos na base do anel herniário que após liberação foi seccionado, seguido de interiorização abdominal do conteúdo herniário (epiplon).

Para a oclusão do anel herniário deve-se utilizar sutura em jaquetão, somada à invaginação das aponeuroses dos músculos abdominais, através de pontos simples separados e fio inabsorvível ou categute cromado. Em hérnias recidivadas o uso de suturas simples com fio de algodão três zeros, com pontos de relaxamento tem apresentado bons resultados (PRATES, 2008). Neste caso não foram realizadas as suturas indicadas pelo autor. Realizou-se sutura de Wolf do anel herniário com fio de nylon n040 e redução dos espaços mortos com sutura continua e a dermorrafia com sutura simples separada. 
SOUSA, G.V. et al. Hérnia umbilical em caprino: Relato de caso. PUBVET, Londrina, V. 7, N. 13, Ed. 236, Art. 1558, Julho, 2013.

Considerando o tamanho do saco herniário, a largura do orifício e após verificar que a resolução espontânea ou métodos não-cirúrgicos não seriam suficientes para solucionar o problema optou-se pelo tratamento cirúrgico. A redução da hérnia, por ter sido realizada com o saco herniário fechado, diminuiu as chances de contaminação bacteriana da cavidade abdominal. Após o tratamento cirúrgico o paciente foi submetido ao pósoperatório com aplicações de antibiótico, antiinflamatório e cuidados diários com a ferida cirúrgica. Após o período de dez dias o paciente recebeu alta totalmente recuperado e com sinais clínicos dentro dos parâmetros normais para a espécie.

\section{Conclusão}

Concluímos que a técnica cirúrgica empregada possibilitou resultados satisfatórios, devido a não abertura do anel herniário, uso da sutura de Wolf e a não contaminação da cavidade abdominal. Essa manobra cirúrgica é bastante empregada em casos de hérnias com anéis de pequeno diâmetro como ocorreu no presente caso descrito. Algumas medidas devem ser usadas para minimizar a ocorrência de hérnias umbilicais em pequenos ruminantes, tais como: ter cuidado com a manipulação dos neonatos e assepsia do umbigo logo após o parto, tratar possíveis infecções umbilicais o mais rápido possível, evitar exercícios exaustivos e traumatismos na região abdominal.

\section{Referências}

ADAMS, R. Urachal and umbilical disease. In: KOTERBA, A.M. et al. Equine clinical neonatology. Philadelphia: Lea \& Febiger, p.482-490, 1990.

BOJRAB, M. J. Técnica Atuais em Cirurgias de Pequenos Animais. 3.ed. São Paulo : Roca, p.410-411, 1996.

FOSSUM, T. W.Cirurgia de Pequenos Animais. São Paulo, Editora Roca.p. 196-197, 2002.

HICKMAN, J. W. Atlas de Cirurgia Veterinária. 2.ed. Rio de Janeiro : Guanabara Koogan, p. $101-108,1983$. 
HUNT, G. B. Hernia repair: principles \& practices. North American Veterinary Conference, Sidney, Austrália. 2006.

KRAUS, K. H. Hérnias. In: BOJRAB M. J. (Ed). Técnicas atuais em cirurgia de pequenos animais. 3.ed. São Paulo:Roca, pp.410-414, 1996.

LISCHER, C. J.; STEINER, A. Ultrasonography of the umbilicus in calves. Part 2: Ultrasonography, diagnosis and treatment of umbilical diseases. Schweizer Archiv für Tierheilkunde. v.136, n.6/7, p.227-241, 1994.

NGUHIU MWANGI, J. A., MUNYUA S. J. M., MBITHI P. F. M., MBIUKI, S. M. \& MOGOA E. G. M. How to improve the prognosis of ventral abdominal hernias in large animals: "modified" overlapping technique. Bulletin of Animal Health Production African. 39: 315-320, 1991.

ORSINI, J. A. Management of umbilical hernias in the horse: treatment options and potencial complications. Equine Veterinary Education, v.9, n.1, p.7-10, 1997.

PRATES, N. C. O Umbigo e a Saúde do Bezerro. 2008. Disponível em < http://www.rehagro.com.br/siterehagro/publicacao.do?cdnoticia=1780>. Acesso em: 15 de ago. 2011.

PUGH D. G.. Clínica de ovinos e caprinos / editado por; [tradução e revisão científica José Jurandir Fagliari], - São Paulo: Roca, 2004.

REBHUM, W. C. Doenças do Gado Leiteiro: São Paulo: Roca, p. 285-286, 2000.

SILVA L. A. F., FIORAVANTI M. C. S., EURIDES D., JULIANO R. S., ACYPRESTE C. S. \& BORGES G. T. Sobreposição com invaginações das aponeuroses dos músculos abdominais no reparo de hérnias umbilicais em bovinos. Veterinária Notícias. 5: 63-67, 1999.

SLLATER, D. H. Manual de Cirurgia de Pequenos Animais. São Paulo, Editora Manole.p. 431.1998.

SOUZA, D. B.; ABILIO, E. J. Hérnia perineal em cães - revisão de literatura. Revista Clinica Veterinária, n. 68, p. 78-86, maio/jun. 2007.

STOCKWELL, C.; FISHER, A. T. Enterocutaneous fistula with umbilical hernia. Pulse, v.32, n.1, p.18,1989. 